Revista de Gestão e Secretariado - GeSeC

e-ISSN: $2178-9010$

DOI: $10.7769 /$ gesec.7i2.597

Organização: SINSESP

Editor Científico: Cibele Barsalini Martins

Avaliação: Double Blind Review pelo SEER/OJS

Revisão: Gramatical, normativa e de formatacão

REVISTA DE GESTÃO E SECRETARIADO

MANAGEMENT AND ADMINISTRATIVE PROFESSIONAL REVIEW

\title{
AUTORIA CIENTÍFICA: POR QUE TANTA POLÊMICA?
}

\section{SCIENTIFIC AUTHORSHIP: WHY SO MUCH CONTROVERSY?}

\author{
Gilson L. Volpato \\ Livre-docente em Fisiologia Animal pela UNESP, São Paulo (Brasil) \\ Departamento de Fisiologia, Instituto de Biociências de Botucatu, UNESP, São Paulo (Brasil). \\ E-mail: volpgil@gmail.com
}




\section{AUTORIA CIENTÍfICA: POR QUE TANTA POLÊMICA?}

\section{RESUMO}

Os critérios para autoria científica ainda carecem de consenso entre cientistas, dando margem a especulações que, algumas vezes, apenas justificam o injustificável. Neste texto, meu foco é na ciência empírica e eu proponho que participações em coleta de dados (CD) ou fornecimento de recursos materiais (RM) para a pesquisa não são condições suficientes, nem necessárias, para se atribuir autoria em textos científicos. Após apresentar as bases teóricas dessa proposta, mostro dados que indicam que essas bases têm sido usadas em magnitude ampla na ciência internacional, o que torna o debate ainda mais relevante. Ao final proponho separar as participações na pesquisa científica em autoria, colaboração e agradecimento, de forma a valorizar cada grupo de atuação, sem perder suas peculiaridades.

Palavras-Chave: Autoria. Publicação Científica. 


\title{
SCIENTIFIC AUTHORSHIP: WHY SO MUCH CONTROVERSY?
}

\begin{abstract}
Criteria for scientific authorship still lack of universal consensus among scientists, thus rising speculations that, sometimes, only justify the unjustifiable. In this text, my focus is the empirical science and I propose that participation in data collection (DC) or provision of material resources (MR) for the research are neither sufficient, nor necessary, conditions to warrant authorship in scientific texts. After presenting the main theoretical bases of my argument, I show some data supporting that such participations (DC and/or MR) have been largely used for assignment of scientific authorship in the international literature, thus making this debate more relevant. Finally, I propose separate the participation in a scientific study in three classes: authorship, collaboration and acknowledgements, thus valorizing each of these participations, but not contradicting its peculiarities in the process of building scientific knowledge.
\end{abstract}

Keywords: Authorship. Scientific Publication 


\section{INTRODUÇÃO}

A publicação científica tem sido usada como um dos principais elementos para avaliar a capacidade dos cientistas. De fato, esperamos que um cientista divulgue suas descobertas e construções teóricas para a comunidade científica, na tentativa de agregar valor à rede de conhecimentos científicos pré-existente, seja melhor fundamentando ou modificando essa rede. E deve ser exatamente a partir da qualidade desse conhecimento produzido que melhor podemos inferir a qualidade da atividade dos cientistas.

Essa aferição da qualidade do cientista se desdobra em méritos. Por exemplo, é a partir de tais análises que se atribuem distribuição de auxílios financeiros para projetos, bolsas e também cargos em instituições públicas ou privadas. Por esses ganhos, a avaliação se reveste de extrema importância e seriedade. Porém, nesse quadro avaliatório, inferências erradas sobre a qualidade de um cientista certamente acarretam injustiças sociais, desde moderadas até as mais profundas. Dessas injustiças, por exemplo, um profissional pode desistir da carreira científica, perder a chance de realizar um projeto de excelência em detrimento de outros de menor qualidade, ou mesmo perder a vaga de emprego para alguém de menor relevância para a sociedade.

Embora nessa problemática a discussão trivial recaia nos meios de se aferir qualidade à publicação científica, aqui foco numa outra questão crucial: quem merece receber os méritos da publicação? Em outras palavras, quais são os critérios genuínos para se aferir autoria num trabalho científico? Note que erros nesses critérios desdobram nas injustiças sociais referidas acima. Ou seja, quem comete erros atribuindo autoria a quem de fato não a merece contribui para que verbas e outros merecimentos ligados ao trabalho sejam desviados para pessoas que dele não deveriam fazer parte. Esse desvio, que no Brasil significará muito frequentemente "desvio de verba pública" é inadmissível numa comunidade que deveria zelar pela boa conduta e exemplo para todo o país.

Tais erros podem decorrer de duas situações. De um lado, o caráter desonesto do pesquisador; de outro, a ignorância conceitual que leva a qualificações equivocadas. Os casos de desonestidade intelectual não serão resolvidos por este texto, e talvez por nenhum outro. São coautorias atribuídas por meio de troca de favores. Aqui minha proposta é bem mais modesta, focando nos diversos pesquisadores honestos que temos, mas que por alguma desorientação conceitual possam atribuir, ou aceitar, autoria a quem conceitualmente não é autor do trabalho. A estes últimos nos compete fornecer subsídios para um bom entendimento da problemática da

Revista de Gestão e Secretariado -GeSec, São Paulo, v. 7, n. 2, p 213-227,mai./ago. 2016. 
autoria; aos outros, apenas lamentar e não nos negar a ir às últimas instâncias legais quando assim as oportunidades propiciarem.

A questão seguinte é saber exatamente quais os erros conceituais na aferição de autoria em um trabalho científico. Para tal empreitada, não usarei propostas cabalísticas e muito menos critérios baseados no costume. Prefiro perguntar à própria metodologia científica o que é ser autor de um trabalho científico. Para isso, teremos que entender o que é um trabalho científico (por simplicidade, me referirei a artigo, mas engloba quaisquer textos que construam conhecimento novo) e sua função na ciência. Isso nos ajudará a entender o que defendo serem os dois principais erros conceituais na aferição de autoria científica, responsável por muitas injustiças na diferenciação qualitativa entre cientistas: "coleta de dados - CD" e "propiciação de recursos materiais - RM".

\section{BASES CONCEITUAIS}

\subsection{A Ciência}

Fazer ciência significa construir novos conhecimentos dentro da rede de conhecimento científico pré-existente. Esse conhecimento não é estático, mas dinâmico, e sua construção contempla inclusão de novas informações, bem como modificação do que se aceita, ou mesmo fortalecimento de ideias ainda controversas. Em todos esses casos deve haver alguma mudança. Tal conhecimento é produzido pelas pesquisas científicas e se torna público com a publicação em revista científica. Porém, sua inclusão nessa rede de conhecimento científico, a ciência, só ocorre quando parcela significativa da comunidade científica aceita o conhecimento produzido na publicação. Uma vez que o conhecimento passa a ser aceito pelos cientistas, mesmo que existam algumas controvérsias, ele pode ser incorporado em textos menos herméticos, como livros da especialidade, de forma a adentrarem um mundo educacional mais amplo. E o que de um artigo científico entra nessa literatura mais ampla?

A vasta maioria das informações num livro texto de ensino de alguma disciplina de ciência é composta de conclusões derivadas de artigos científicos. Quando explicamos um conceito (por ex., o que é estresse), lidamos com a conclusão que o proponente desse conceito (Dr. Hans Selye) defendeu em seu trabalho original. Se o livro inclui a explicação de algum mecanismo de ação, cada elemento e cada etapa desse processo dinâmico refletem geralmente conclusões obtidas num conjunto de artigos específicos. Eventualmente, os livros textos podem

Revista de Gestão e Secretariado-GeSec, São Paulo, v. 7, n. 2, p 213-227, mai./ago. 2016. 
trazer alguns resultados ou mesmo algumas metodologias, mas as informações mais presentes são as conclusões. Mesmo quando resultados ou metodologias são apresentadas nos livros, o objetivo é alguma generalização conceitual, mesmo que de caráter mais metodológico ou tecnológico. Isso se coaduna com o caráter teórico intrínseco da ciência, que visa explicar o que são os elementos do mundo e como se relacionam entre si, de forma a dar ferramentas conceituais para o ser humano compreender o mundo e atuar nele segundo suas próprias diretrizes.

\subsection{As Evidências na Ciência Empírica}

Outro aspecto para nos auxiliar na compreensão do fazer ciência é entender como esses conceitos são construídos. Embora para o processo de criatividade não haja regras explícitas, um elemento básico e essencial em toda a ciência empírica, nas três áreas do conhecimento (Biológicas, Exatas e Humanas), é a existência de evidência confiável e de caráter "universal" que apoie as conclusões do estudo. Tais evidências são representadas em duas fontes. Uma delas são os resultados obtidos pelos cientistas em suas pesquisas. Se você não apresentar resultados que justifiquem suas conclusões, a possibilidade de aceitação na ciência empírica é praticamente nula. Não se confunde aqui as ciências formais, como Lógica e Matemática, que necessariamente não se preocupam com a base empírica, mas com um raciocínio forte que, de axiomas, chega a conclusões. E não há outra forma de ciência senão essas duas, porém com um mesmo objetivo: construir explanações teóricas sobre o mundo. As ciências formais são, muitas vezes, úteis como linguagens pelas quais podemos estudar o mundo. E, por mundo, entendemos tudo o que de razoável conseguimos perceber que nele existe, sem discriminações entre o mundo físico e o mundo biológico englobando todas as formas vivas. Com isso, o objetivo da ciência é entender os organismos vivos, o meio ambiente físico-químico e também suas interações, na expectativa de livrar o homem da ignorância, o que esperamos que possa minimizar nosso sofrimento.

Para tal empreitada, a ciência conta com seu método mais óbvio e forte, que é sua base empírica. Ela é nada mais do que as evidências que chegam até o cientista e que ele pode mostrar, no mínimo, a outros cientistas (esse é o caráter "universal" expresso no parágrafo acima). Neste aspecto, evidências pessoais não são aceitas para fundamentar conclusões. Mesmo que esse extremismo possa desviar o homem de aspectos importantes para o entendimento do universo, certamente os erros de se admitir experiências pessoais no processo

Revista de Gestão e Secretariado-GeSec, São Paulo, v. 7, n. 2, p 213-227,mai./ago. 2016. 
de construção científica seriam muito maiores, transformando o ambiente científico numa torre de Babel. A breve história da ciência revelou a adequação dessas apostas metodológicas e epistemológicas, dando suporte à empreitada tecnológica humana. Foi essa postura que fez o homem atingir marte, a entrar no mundo da criança antes que ela nasça, a descobrir nossos inimigos invisíveis, a nos mostrar os desvios de nossos pensamentos, a entender o quanto as emoções interagem com nosso corpo físico, a perceber a fragilidade de nosso planeta, a perceber e explorar fontes alternativas de alimento e energia etc. Hoje temos uma concepção mais bem acertada sobre o universo devido a essa proposta metodológica; expectativas e desejos são importantes, mas contrastar com a realidade é fundamental.

Dois exemplos clássicos nos mostram a importância da base empírica para o cientista. Quando Einstein propôs sua teoria geral da relatividade, ela foi relativamente aceita, mas o desfecho final que o consagrou "o grande cientista" ocorreu somente após essa teoria superar uma predição factual. A base empírica chave para essa predição foi detectada a partir de um eclipse que foi fotografado (evidência empírica não individual) em 1919 nas cidades de Ilha do Príncipe, na África, e Sobral, no Brasil. O fato registrado não contrariou uma das importantes implicações da teoria de Einstein, mas contrariou a teoria vigente e concorrente, proposta por Newton. Foi um eclipse, apenas um fato (fotos)... mas deu a força que os cientistas empíricos precisam. Lógico que é um fato rodeado de teorias, o que atende ao necessário para se construir conhecimento científico.

Outro exemplo é o da descoberta do bóson de Higgs. O campo de Higgs, que pressupunha a partícula de Higgs, foi proposto há cerca de 50 anos, mas sua aceitação pela ciência ocorre de forma contundente apenas quando essa partícula foi detectada experimentalmente. Este exemplo mostra que teoria e corroboração empírica andam juntas na ciência. Muitas vezes a teoria vem antes. Há vários casos de atribuição do prêmio Nobel conjuntamente aos cientistas proponentes da ideia e àqueles que conseguem base empírica forte para sustentá-la, geralmente num lapso de alguns anos ou décadas. No caso do bóson de Higgs, isso ocorreu com a evidência obtida (O’Luanaigh, 2013) com a detecção da tal partícula, cujo peso foi estimado de forma mais contundente em Aad et al. (2015).

Essa mesma posição em relação à base empírica na construção do conhecimento é o que faz hoje certos neurocientistas questionarem a validade da psicanálise de Freud. Embora seja natural que em certos momentos da construção do conhecimento os cientistas proponham alguns elementos especulativos para dar coerência explicativa às suas teorias, espera-se que esses elementos sejam validados pelas evidências no futuro. A falta dessa validação contribui Revista de Gestão e Secretariado -GeSec, São Paulo, v. 7, n. 2, p 213-227, mai./ago. 2016. 
para aumentar a desconfiança sobre a teoria. A seleção natural personificada na pessoa de Charles Darwin também é um processo que não pode ser testado diretamente pelas evidências empíricas, mas que foi fortalecido pelos conhecimentos da genética e da biologia molecular, cujos achados sustentam hipóteses necessárias que compõem o escopo central da teoria.

Dos expostos acima, fica claro que na ciência o importante são as ideias, mas que elas precisam ter coerência lógica forte ou evidências contundentes. Isso não se confunde com verdade, pois esta não faz parte do mundo da ciência, apenas da religião. A verdade científica é provisória. Pergunte a um cientista qual será a explicação aceita sobre determinado fenômeno daqui há 200 anos; pergunte agora a um religioso se o deus que ele acredita estará vivo daqui há 200 anos. Essa é a diferença fundamental entre essas duas posturas sobre a verdade. E mais, o religioso pode aceitar verdades com base em evidências do mundo, mas aceita também as evidências restritas às suas experiências individuais, o que o cientista não pode se valer para fundamentar suas conclusões. As chances de erros ao se usar experiências individuais que não podem ser expandidas a outros para construir conhecimento são grandes, pois o ser humano geralmente se esforça para comprovar suas convicções. A metodologia científica, longe de ser um corpo objetivo de análise do mundo, nos dá estratégias metodológicas que minimizam tais efeitos.

Além dessas evidências empíricas, o cientista também se vale de evidências indiretas que estão disponíveis na literatura científica. Assim, ao usarmos uma informação da literatura, ela terá maior força para os cientistas se na obra citada houver as evidências empíricas que sustentam e validam essa informação. Com isso, o argumento se desenvolve baseado em evidências empíricas, sejam originais do seu estudo (pois não havia na literatura) ou já publicadas (citações). Note que um artigo de revisão da literatura é um discurso científico que busca dar uma nova "leitura" sobre conclusões e fatos já publicados num determinado tema. Pode, inclusive, ser desenvolvido para testar hipóteses específicas a partir de uma análise das evidências e conclusões disponíveis. Tais artigos de revisão não carecem de base empírica.

\subsection{A Força da Base Empírica na Construção das Conclusões Científicas}

Embora a crença no início da ciência empírica tenha sido fortemente conduzida para achar que os dados (evidências, bases empíricas) determinavam as conclusões, a breve existência da ciência empírica já desmontou tal crença. É óbvio que isso ainda persiste para muitos "cientistas", mas não podemos confundir esse equívoco com ciência. A crença na 
objetividade dos dados (base empírica) também foi afastada. Dados inexoravelmente objetivos, que são vistos sempre pelo mesmo jeito por qualquer outro cientista, são uma crença já descartada na ciência. Ao olhar as pistas (evidências), o cientista não consegue impingir um olhar neutro. Isso também faz parte da ciência. Hoje é evidente que as bases empíricas são "lidas" pelo cientista; ele as interpreta. O medo de alguns pesquisadores em produzir algo subjetivo tem afastado muitos deles da chance de fazer ciência. Insistem no erro original da crença indutivista e se esquecem de que o ser humano tem um aparato perceptual bastante limitado para captar as evidências do mundo, bem como que o olhar interpretativo humano requer comparações e referenciais com base em suas experiências mantidas na memória, o que lhes impedem de uma abordagem puramente objetiva. Tente imaginar como outros animais percebem o mundo, com seus órgãos sensoriais mais potentes, ou menos potentes, que os nossos. A extensão sensorial por meio de equipamentos não resolveu esse problema. Além disso, na construção do conhecimento, as evidências sempre são incompletas frente ao conhecimento produzido, o que requer interpretação; dessa forma, uma construção não plenamente objetiva como muitos gostariam.

Dois exemplos clássicos auxiliam para entendermos o conceito deste tópico. Um deles é o da descrição da molécula do DNA personificada nas pessoas de Watson e Crick, em 1953. Na época, buscavam entender como era a estrutura dessa molécula. A grande divergência era que muitos, inclusive grandes cientistas como Linus Pauling, imaginavam que havia três fitas de aminoácidos. A evidência empírica mais importante veio de imagens de raio $\mathrm{X}$ dessas moléculas, tiradas por Rosalin Franklin. No entanto, foram Watson e Crick quem conseguiram dar o salto teórico necessário para transformarem essa imagem de raio X (que se parecia mais com a foto frontal de uma hélice de avião girando em alta velocidade) na famosa imagem de uma escada espiral (a dupla hélice, que é um conceito da geometria), que foi construída com a suposição da existência de apenas duas fitas de aminoácidos. No trabalho original, descrevem como visualizaram, da imagem do raio $\mathrm{X}$ do DNA, a estrutura tridimensional do DNA, mais tarde corroborada, em sua base geral, pela biologia molecular. A imagem do raio X não era automaticamente determinante do formato do DNA; exigia interpretação.

Outro exemplo clássico é o caso da evolução biológica. Tanto Lamarck quanto Charles Darwin propuseram mecanismos para a evolução biológica. Embora em períodos diferentes, as evidências que esses cientistas dispunham eram estruturalmente similares. Trabalhavam com as diferentes formas de animais e vegetais. Essas eram as evidências... restava entender como eram produzidas e como as diferentes espécies se originavam. Lamarck

Revista de Gestão e Secretariado -GeSec, São Paulo, v. 7, n. 2, p 213-227,mai./ago. 2016. 
propôs sua teoria em 1809, enquanto Darwin propôs em 1859 - trinta anos após a morte de Lamarck. Note que essas evidências não determinaram suas teorias, mas deram a elas evidências para serem completadas por elaborações imaginativas, lógicas e concordantes com as evidências. Nenhum dos dois acertou sobre a origem das diferenças, mas sobre o mecanismo para se entender as diferentes espécies Darwin foi mais convincente, sendo sua proposta de seleção natural aceita até hoje pela academia, inclusive sendo extrapolada para além da área Biológica, como no caso da teoria evolucionária epistemológica de Karl Popper.

Elaborar conhecimento científico tem isso de maravilhoso. Partimos de pistas, mas precisamos de criatividade, de imaginação para compormos o conhecimento explicativo que une e dá sentido aos fatos que constatamos no mundo. As conclusões dos artigos científicos não são diferentes. Elas vão além dos dados, dando-lhe sentido lógico e no contexto da especialidade. Reduzir a ciência aos dados e imaginar que eles determinam o restante da história do trabalho é não entender como o conhecimento é produzido. Há, certamente, evidências muito fortes e, em alguns casos, podemos até dizer que as ideias decorrentes estão muito ligadas às evidências. Mas à medida que nossas teses e teorias se tornam mais abrangentes, mais distantes ficamos dos fatos e mais avançamos nas teorias científicas. Esse avanço significa, em última análise, explicar mais fenômenos e fatos do mundo.

Embora eu tenha usado exemplos clássicos e abrangentes, os conceitos defendidos acima se aplicam para o cotidiano do cientista. Cada artigo esbarra com essa problemática sobre os dados e as ideias. Há artigos que são negados não devido à negação dos resultados, mas pela negação da interpretação dada pelos autores.

\subsection{A Prática Atual das Publicações se Ajusta às Bases Filosóficas da Ciência}

$\mathrm{Na}$ atualidade, percebo claramente que a comunicação científica nas revistas de maior prestígio se aproxima cada vez mais dos enunciados mais fortes da ciência, enquanto que as revista mais fracas se mantêm presas a conceitos ultrapassados. Isso reforça a ideia de que os erros na redação científica e nas posturas sobre publicação decorrem de erros de ciência, juntamente com erros de comunicação. $\mathrm{O}$ alarmante é que a base da ciência pouco mudou nos últimos séculos, enquanto que as bases comunicacionais na ciência mudaram drasticamente nos últimos 20 anos.

Num artigo científico, o foco central são as conclusões. Mesmo que certo estudo seja repetido, não se tem a ingênua expectativa de que os mesmos resultados sejam obtidos,

Revista de Gestão e Secretariado-GeSec, São Paulo, v. 7, n. 2, p 213-227,mai./ago. 2016. 
mas certamente de que as mesmas conclusões sejam elaboradas. Ou seja, os resultados podem mudar ligeiramente, mas as conclusões se mantêm.

Essa constatação óbvia a partir da compreensão do processo científico tem se tornado prática científica mais contundente na atualidade. Note que recentemente começam a surgir revistas que publicam apenas resultados, como a Scientific Data (http://www.nature.com/sdata/), do grupo Nature. A ideia é que dados individuais (não apenas médias e desvios, por ex.) possam ser compartilhados por outros cientistas, com o intuito de serem reutilizados. Isso decorre da percepção de que os dados não determinam as conclusões, mas são pistas cruciais para os cientistas elaborarem e testarem suas interpretações sobre o mundo.

\subsection{De Volta à Autoria}

Tendo exposto o que considero as bases teóricas suficientes para o raciocínio sobre a autoria científica, retomo o tema. A aceitação de que os dados não determinam as conclusões sustenta algumas implicações para a publicação científica. Por exemplo, sustenta que o texto científico deve ser escrito na primeira pessoa, nos fazendo entender o forte crescimento no número de artigos escritos na primeira pessoa a partir da década de 1990 (chega a 30\% nessa década e $\sim 40 \%$ na década seguinte, com previsão de atingir $50 \%$ na década atual (dados coletados a partir da coleção principal do Web of Science). Mais que isso, nos impulsiona para entendermos que não apenas devemos apresentar nossos resultados, mas mostrar aos leitores o que vimos neles, de forma franca para que entendam nosso ponto de vista antes de criticá-lo.

Embora os desdobramentos acima venham sendo gradativamente incorporados na prática do cientista, poucos avanços ocorrem em relação à autoria. Aqui nos interessa o desdobramento para a autoria. Considero que a essência do conhecimento construído no artigo está nas conclusões e os dados, embora necessários para a argumentação científica, não são suficientes para que cheguemos às conclusões. Esse é o ponto crucial para desdobrarmos sobre a autoria.

Acrescente a esse quadro a noção de que os autores de um trabalho científico devem ser os responsáveis pela construção de sua essência, as conclusões. Na realidade, todo o trabalho é construído como se fosse um argumento lógico (com premissas - metodologia, resultados e

literatura - para validarem as conclusões). A quem compete tal argumentação, se não aos autores? Nesse processo, as evidências, sejam resultados (baseados na metodologia descrita)

Revista de Gestão e Secretariado-GeSec, São Paulo, v. 7, n. 2, p 213-227, mai./ago. 2016. 
originais ou informações presentes na literatura científica, servem como premissas que sustentam, por um raciocínio lógico, as conclusões.

O preceito enunciado acima não é algo válido apenas para estudos de alcance mais restrito, ou que metodologicamente requerem menor número de participantes. É um conceito mais amplo que supera inclusive as tendências mais recentes de áreas que envolvem a participação de centenas ou milhares de cientistas. Há na literatura várias publicações onde se percebe claramente os autores do trabalho e agradecimentos a pessoas que contribuíram com coleta de dados, arranjos de materiais e outras instâncias que não se responsabilizam pela argumentação científica do texto. Estudos com participações multidisciplinares, inclusive com coleta de dados em ambientes mais globais, requerem muitas pessoas num esforço coletivo para se obter dados para a consolidação de uma resposta a uma pergunta de interesse a esses cientistas. Mas, empreitadas igualmente grandes não são novidades recentes. Algumas expedições científicas requeriam muitos participantes, seja nas embarcações ou mesmo na coleta de dados do mundo natural. Mas as conclusões sempre ficaram sob a responsabilidade dos cientistas que a produziram. Portanto, não cabe uma análise sobre o número de autores, pois se houver dois autores e um deles não for genuinamente autor do trabalho, houve erro. A questão é termos referenciais adequados para nossas decisões sobre quem são os autores na pesquisa que participamos.

\section{DOIS ERROS FUNDAMENTAIS NO CRITÉRIO DE AUTORIA CIENTÍFICA}

A questão crucial que defendo neste texto é que a mera coleta de dados e/ou propiciação de materiais e condições físicas para a pesquisa não são critérios suficientes para assegurar autoria num trabalho científico. Esta noção vem da ideia de que a essência de um trabalho científico é a conclusão, sendo as evidências (metodologia e resultados) bases necessárias, porém não suficientes, para se construir toda a argumentação e conclusões do estudo. Para simplificar o discurso, chamarei esses dois equívocos de "coleta de dados - CD" e "fornecimento de recursos materiais - RM".

Uma alegação comum na defesa de que participações em CD e RM garantem autoria no trabalho é que a pesquisa não existiria sem essas participações. De fato, é bem possível que não houvesse a pesquisa. Essa alegação incute o erro de que meios significam fins. Há tantas outras situações que inviabilizariam as pesquisas e, nem por isso, pertencem ao quadro dos autores. Se não houvessem as empresas que produzem certos instrumentos, algumas

Revista de Gestão e Secretariado-GeSec, São Paulo, v. 7, n. 2, p 213-227,mai./ago. 2016. 
pesquisas não seriam possíveis. Há pesquisas que terceirizam pessoas, ou mesmo certos laboratórios, para coleta de dados, sem que isso signifique coautoria. Olhemos também por outro ângulo: você gostaria de ser responsabilizado por um documento do qual você forneceu informações, mas não elaborou a proposta final? Não se trata de concordar com a proposta final, pois concordamos com muitos textos que lemos; se trata de se achar dono daquela informação. Quando fornecemos informações para uma reportagem, somos dono do texto final produzido pelo repórter? É nesse sentido que os dados, e as condições materiais decorrentes, são necessários para a pesquisa, mas não são suficientes para a autoria. Há um salto a partir dessa prática, que chega ao âmago da pesquisa e que não podemos apenas dar ciência a colaboradores para validá-los como coautores. $\mathrm{O}$ artigo científico defende fatos e, principalmente, ideias numa postura argumentativa para tentar convencer outros cientistas de que o olhar apresentado no texto deve ser aceito pela comunidade científica. Essa argumentação e o novo olhar apresentado é a essência do texto e representa, segundo entendo, a essência da participação dos autores no trabalho. Veja que negar CD e RM como elementos suficientes para autoria se adequa também para pesquisas de revisão da literatura (que produzem conhecimento novo) e estudos que envolvem reanálise de dados publicados por outros cientistas. Por isso, me parece que a questão da autoria merece ser tratada de forma diferente do que tem sido praticada regularmente em nosso meio.

\subsection{Uma Breve Análise Sobre a Realidade}

Para verificar se minha suspeita de que dois desses equívocos (CD e RM) são mais do que expectativas racionalistas, fiz uma coleta de dados, mesmo que incipiente, numa revista de escopo amplo e cujo crivo para publicação não restringe demasiadamente os que pretendem publicar. Sorteei artigos do ano de 2015, com dados originais e publicados na revista PLOS ONE, no entendimento de que vasculharia um universo de conteúdo mais diversificado dentro da ciência. Nesses artigos, analisei os motivos atribuídos pelos próprios autores para inclusão de cada pesquisador no quadro de autores.

A pequena amostra sorteada (35 artigos, num total de 254 autores) revelou motivos de autoria que classifiquei em 7 classes: concepção da pesquisa; financiamento da pesquisa $(\mathrm{RM})$; coleta de dados (CD); análise de dados; realização de análise estatística; redação do manuscrito e revisão do manuscrito. Dessas classes, foquei as análises nos dois motivos que, pelo exposto acima, refletem erro conceitual na atribuição de autoria: CD e RM. Não eximo

Revista de Gestão e Secretariado-GeSec, São Paulo, v. 7, n. 2, p 213-227,mai./ago. 2016. 
outros erros, como inserção de amigos, editores da revista para facilitar o processo, superiores hierárquicos, componentes do grupo etc.; mas tais erros ultrapassam equívocos teóricos e entram no campo da desonestidade, o que não resolveremos com este texto. Procuro focar nos equívocos que levam pessoas honestas a cometerem erros de autoria, levando às consequências prejudiciais que independem do motivo pelo qual determinado autor foi incluído erroneamente no corpo de autores do trabalho.

Em suma, a análise dos principais dados constatados nessa breve inspeção das autorias indicou que o quadro teórico esboçado até aqui é frequente e deve ser considerado seriamente nas questões avaliatórias. Mesmo que os números possam ser modificados ligeiramente, pela pequena base amostral, as concepções que extraio daqui me parecem válidas. Dos 254 autores analisados, 64 (25,2\%) foram incluídos com base nos critérios CD e RM. Dessas inclusões, 39 (60,9\%) foram exclusivamente decorrentes de CD e 23 (35,9\%) de RM. Além desses, 2 autores $(3,1 \%)$ foram incluídos com os dois requisitos (CD e RM). Olhando agora para o número de artigos, dos 35 examinados, 18 (51,4\%) apresentaram como requisito suficiente para autoria algum dos dois tipos investigados (CD e RM). Desses 18 artigos, apenas $6(33,3 \%)$ incluíram apenas CD e $2(11,1 \%)$ apenas RM. Mesmo que sejam dados incipientes, esta breve análise me permite dizer algo sobre esses dois equívocos conceituais na atribuição de autorias científicas. Primeiro, que tais equívocos ocorrem no meio científico. Segundo, que o percentual não parece ser tão ínfimo quanto desejaríamos. Terceiro, cada um desses erros tem sido suficiente para inclusão de pesquisadores no rol da autoria.

Derivado dessas constatações, fica clara a necessidade de discussões mais profundas sobre o papel da CD e de RM na atribuição de autoria científica, bem como das bases conceituais que os caracterizem como erros. Com este texto pretendi ressaltar a necessidade desta discussão no meio científico. Dificilmente o pesquisador que apenas contribuiu com CD e RM defenderá que não são critérios adequados de autoria. Mas a discussão deverá extrapolar nossos casos particulares e adentrar nas razões epistemológicas científicas para tais posições.

\section{PROPOSTA PARA ClaSSIFICAÇÃo DAS PARTICIPAÇÕES EM PESQUiSAS CIENTÍFICAS}

Entendo que há participações que são importantes numa pesquisa científica, mas que não podem ser responsabilizadas pelo teor das conclusões. Como na atualidade a única

Revista de Gestão e Secretariado-GeSec, São Paulo, v. 7, n. 2, p 213-227,mai./ago. 2016. 
forma de se obter o necessário mérito pela participação numa pesquisa científica recai na autoria, ou estamos dentro ou estamos fora e não temos muita oportunidade para reconhecimentos fora desse contexto. Porém, autoria científica não é um relato de participações, mas um atestado de que os autores formularam as ideias contidas no trabalho e as argumentações necessárias para solidificação dessas ideias. Segundo Maddox (1994), os autores devem ser aptos a defender o trabalho perante a comunidade científica. Assim, proponho separar essas participações em autoria, colaboração e agradecimento.

Autoria: são os responsáveis pela parte intelectual da pesquisa, participando ativamente na concepção da pesquisa, acompanhando sua história, contribuindo para a elaboração das conclusões (seja por sua formulação ou por críticas e enfrentamentos necessários para sua manutenção) e elaboração do argumento demonstrativo para defender as conclusões.

Colaboração: são aquelas que não exigem do participante a responsabilidade pelas ideias do trabalho, mas apenas pela parcela de sua participação. Por exemplo, se coletou parte dos dados, deve se responsabilizar por isso. Merece destaque, mas não autoria.

Agradecimento: são todas as participações que, não se enquadrando nos casos acima, ainda assim merecem reconhecimento. São apoios, incentivos e apostas de várias ordens, ou mesmo permissões de uso de certos locais ou materiais, ou mesmo organismos, para que a pesquisa fosse realizada. Essas participações não impingem qualquer tipo de responsabilidade a essas pessoas em relação ao trabalho, diferentemente do que ocorrem com as duas participações acima.

\section{REFERÊNCIAS}

Aad, G. et al. (ATLAS Collaboration, CMS Colaboration). (2015). Combined measurement of the Higgs boson mass in pp collisions at $\sqrt{s}=7$ and $8 \mathrm{TeV}$ with the ATLAS and CMS Experiments. Physical Reviews Letters, vol. 114: $\mathrm{n}^{\circ} 191803$. http://journals.aps.org/prl/abstract/10.1103/PhysRevLett.114.191803 (acessado em 21/08/2016).

Maddox, J. (1994). Making publication more respectable. Nature, vol. 369, pp. 353.

O'Luanaigh, C. (2013). New results indicate that new particle is a Higgs boson. CERN http://home.cern/about/updates/2013/03/new-results-indicate-new-particle-higgs-boson (acessado em 21/08/2016). 